\title{
UTOPIA NEGATIVA E CATÁSTROFE: A ARTE COMO NEGAÇÃO DETERMINADA DA CULTURA ADMINISTRADA NA ESTÉTICA DE ADORNO
}

\author{
Luciana Molina Queiroz ${ }^{1}$ \\ Universidade Estadual de Campinas (UNICAMP) \\ (i) https://orcid.org/0000-0003-3216-0685
}

\begin{abstract}
RESUMO:
Este artigo tem como objetivo principal analisar a relação entre utopia negativa e catástrofe na Estética de Adorno. O filósofo argumenta que a arte moderna é associada a um tipo de utopia que não é uma representação positiva do que a sociedade deveria ser. A utopia negativa apenas mostra o que a sociedade não deveria ser. A obra de arte está então carregada de contradições de uma sociedade não reconciliada. Tal explica por que a arte moderna e nova é tão recorrentemente caracterizada pelo feio, o repulsivo, o negro e o catastrófico. Na formulação de Adorno, a obra de arte se constitui como negação determinada da sociedade administrada. Como tal, a obra de arte é também negação determinada da cultura administrada, isto é, sua constituição é dada pela negação determinada dos padrões da Indústria Cultural e da tradição artística.
\end{abstract}

PALAVRAS - CHAVE: Utopia negativa; Cultura administrada; Catástrofe.

\section{NEGATIVE UTOPIA AND CATASTROPHE: ART AS DETERMINATE NEGATION OF ADMINISTERED CULTURE IN ADORNO'S AESTHETICS}

\section{ABSTRACT:}

\footnotetext{
${ }^{1}$ Mestra em Filosofia pela Universidade Federal de Minas Gerais (UFMG), Minas Gerais Brasil. Doutoranda em Teoria e História Literária na Universidade Estadual de Campinas (UNICAMP), São Paulo - Brasil, com apoio do CNPq. E-mail: lucianamqueiroz@gmail.com.

Utopia negativa e catástrofe: a arte como negação determinada da cultura administrada na estética de Adorno Luciana Molina Queiroz
} 
This paper has as main goal to analyze the relation between negative utopia and catastrophe in Theodor W. Adorno's Aesthetics. The philosopher argues that modern art is associated to a kind of utopia which is not a positive representation of how the society should be. The negative utopia only shows how the society should not be. The artwork thus is charged with the contradictions of an unreconciled society. That explains why modern and new art is so recurrently characterized by the ugly, the repulsive, the dark and the catastrophic. In Adorno's formulation, the artwork is a determinate negation of the administered society. As such, the artwork is also a determinate negation of the administered culture, i.e. your constitution is given by the determinate negation of the culture industry's standards and of art tradition.

KEYWORDS: Negative Utopia; Administered Culture; Catastrophe.

Ao caracterizar o Novo na arte moderna, Adorno o relaciona com a utopia. Essa relação, entretanto, não é tão simples de se compreender a partir de uma visão estereotipada do tema, tendo em vista que, para ele, a utopia na modernidade artística não se apresenta como alusão a terras paradisíacas ou mesmo como uma solução para os problemas da sociedade. Ao invés disso, a utopia se entrelaça aos materiais mais repelentes e desagradáveis. A arte não provê a imagem de uma sociedade reconciliada, mas antes condensa em sua forma as tensões não resolvidas da sociedade, isto é, a arte está a tal ponto impregnada dessas tensões que não é capaz de se desvencilhar delas.

A despeito do que o senso comum e mesmo grande parte dos comentadores especializados dizem acerca do pessimismo resignado de Adorno, este artigo pretende acrescentar outros argumentos a favor da concepção de que o posicionamento estético de Adorno abre uma alternativa bastante crítica e inclusive esperançosa para a sociedade mediante a dimensão utópica da arte.

Ao invés de decretar a morte ou a decadência da arte, o filósofo a partir dela persegue a utopia. Para ele, a mesma é passível de ser encontrada justamente nos recônditos mais sombrios. Naqueles lugares onde a luz não chega e "a vida não vive" (KÜRNBERGER apud ADORNO, 2008a, p. 15). É em Beckett, Kafka e Schönberg que Adorno encontra utopia, dessa forma indicando que a arte catastrófica, cuja produção se acentua na modernidade artística, é a que comumente se revela crítica em relação ao mundo administrado. Mas, uma vez que ela não se expressa por imagens, não se trata de uma utopia positiva, e sim negativa, ou seja, não mostra o que seria o mundo reconciliado, mas antes o que ele não é, desvelando a falsa reconciliação apresentada pela cultura administrada e constituindo-se como cifra do irreconciliado. Nesse sentido, a obra de arte é utópica porque se torna negação determinada da cultura administrada. 
Utopia e realidade na arte são consideradas por Adorno como possuindo uma relação complexa. A mesma não ocorreria pela produção de uma "mensagem", pois, como se lê no aforismo de Minima Moralia "Cinza e cinza", a mensagem "reifica a resistência contra a reificação" (ADORNO, 2008a, p. 198), também inserindo-se na lógica instrumental predominante na contemporaneidade. Ora, a mensagem é justamente um dos grandes recursos da indústria cultural. Por essa razão é rejeitada pela arte que resiste ao mundo administrado.

Adorno é crítico da concepção de que a comunicação deveria prevalecer nas obras de arte. Para ele, a incomunicabilidade adquire um significado crítico e, assim, intrinsecamente transformador. Por extensão, a existência de uma arte conservadora é por si só uma contradição. Ingenuidade seria pensar que a arte poderia apenas ser nortear pela realidade: "A ideia de uma obra de arte conservadora contém algo de absurdo. Ao separarem-se enfaticamente do mundo empírico, as obras de arte testemunham que este mesmo mundo deve tornar-se outro, esquemas não conscientes da sua transformação" (ADORNO, 2008b, p. 268).

Adorno não só se mostrou cético em relação às obras de arte mais abertamente engajadas ao compreendê-las como insuficientemente críticas em relação à sociedade como também apostou no caráter utópico de obras de arte que não mostravam utopias colocadas positivamente. $O$ fato de $o$ filósofo não conceber a utopia como concreta e positiva repercute no modo como ele avalia a arte moderna, na medida em que foi possível a ele conceber obras de arte acentuadamente catastróficas, tais como as de Schönberg, Beckett e Kafka, como obras de arte utópicas, indo em sentido contrário à parte significativa da tradição hegeliano-marxista clássica (mais notadamente Lukács), que via no modernismo um retrato da decadência artística.

Esse aspecto fundamental de originalidade do pensamento de Adorno reivindica que se aclare como o filósofo recebe influências da Ilustração e do marxismo ao relacionar o ideal emancipatório à arte nova. A concepção adorniana põe em evidência um aspecto negligenciado por grande parte dos estetas e filósofos, ao demonstrar a possibilidade de que obras de arte não claramente vinculadas a utopias político-sociais sejam analisadas por seu teor utópico. Sendo assim, a concepção de Adorno ainda se mantém profundamente atual e crítica, ao evidenciar a possibilidade de o conceito de utopia permanecer relevante para a estética e a arte contemporâneas.

Por mais mudanças que tenham havido na passagem do moderno para o contemporâneo, ainda é evidente o farto uso que esse último faz de elementos sombrios e repelentes. A noção de que a utopia se vincula à catástrofe mantém-se atual, ainda que, em muitos casos, os artistas declarem não realizar uma arte utópica. Adorno também diria sobre isso que mais relevante do que consultar os artistas sobre as obras que realizaram é 
empreender a crítica imanente das obras, pois elas absorvem estratos da sociedade que escapam às intenções e desejos dos próprios artistas.

\section{A arte como negação determinada da tradição}

Há certamente uma ampla gama de comentadores que notam o quanto a reflexão adorniana sobre arte busca expressar a incompatibilidade da Estética tradicional com a arte nova, moderna, que possui características e mesmo tarefas próprias. De acordo com isso, é possível ler nas Minima Moralia que "a tarefa da arte hoje consiste em introduzir caos na ordem" (ADORNO, 2008a, p. 219).

Na concepção de Bolaños (2007), é possível compreender que, para Adorno, como crítica da reificação, a arte denuncia a inverdade do todo ${ }^{2}$. Nesse sentido, a "ordem" representa a administração, que adquire caráter afirmativo e ideológico. A arte não busca a aparência de reconciliação, de modo que é contra a ordem do mundo administrado que ela se torna caótica.

Esse tema é retomado na Teoria estética sob a chave de compreensão de que o caótico advém do processo de espiritualização da arte, em ascensão na modernidade artística:

Os teoremas, segundo os quais a arte deveria trazer a ordem e, sobretudo, uma ordem sensivelmente concreta, não classificatoriamente abstracta, à diversidade caótica do que aparece ou da própria natureza, suprimem de modo idealista o telos da espiritualização estética: permitir que às figuras históricas do natural e da sua subordinação caiba o que lhes é próprio. Por conseguinte, a posição do processo de espiritualização quanto ao caótico tem o seu índice histórico. Repetidamente se disse, em primeiro lugar Karl Kraus, que, na sociedade total, a arte devia antes introduzir o caos na ordem, e não o inverso. Os aspectos caóticos da arte qualitativamente nova só à primeira vista estão em conflito com esta, com o seu espírito. São as cifras da crítica da segunda natureza que é medíocre: igualmente caótica é, em verdade, a ordem. O momento caótico e a espiritualização radical convergem na recusa da vulgaridade das representações bem lavradas do existente [...] (ADORNO, 2008b, p. 149).

A espiritualização, derivada do progresso da consciência, determina que "só a arte radicalmente espiritualizada é ainda possível, toda a outra é pueril” (ADORNO, 2008b, p. 146). Ela torna possível que elementos excluídos da arte desde a Antiguidade Clássica por serem considerados

\footnotetext{
2 "In this sense, art is negative; as a critique of a society damaged by reification, art amounts to the exposure of the "untruthfulness" of the whole" (BOLAÑOS, 2007, p. 30). "Nesse sentido, a arte é negativa; como crítica da sociedade lesada pela reificação, a arte corresponde à exposição da "falsidade" do todo." (Tradução nossa)
} 
demasiado repelentes sejam inseridos na arte nova. Adorno exemplifica que a espiritualização no fauvisme elege como programa a primitividade e a barbárie, e que essa "regressão é a sombra da resistência à cultura afirmativa" (ADORNO, 2008b, p. 147). Outro exemplo disso é a música nova realizada pela Escola de Viena. Censurada pelos tradicionalistas até mesmo mais por seu intelectualismo do que pela dissonância, é possível se constatar que nela emerge a autoconsciência da arte. Ao discutir a caracterização da nova música no ensaio Schönberg e o Progresso, Adorno afirmaria que "Os shocks do incompreensível, que a técnica artística distribui na época de sua falta de sentido e insensatez, se invertem. Dão um sentido ao mundo sem sentido" (ADORNO, 2002, p. 107).

As passagens que discutem a relação entre o artístico e o caos expressam que está colocada para a arte de hoje uma tarefa específica, que determina a radical distinção entre a arte atual e as que a precederam. A espiritualização toma parte nesse processo, colocando-se contrariamente às "representações bem lavradas do existente". Hoje, toda produção artística comprometida com o seu teor de verdade denuncia a "ordem" do mundo administrado e a racionalidade instrumental como irracionais. No entanto, a arte em questão não é produzida como se pudesse estar à parte da sociedade que critica. As obras ostentam cicatrizes derivadas do mundo administrado, de onde derivam. Ao narrador contemporâneo não é possível contar histórias à semelhança dos contadores de épocas anteriores. Na música, a consonância se torna uma inverdade. A pintura, por sua vez, é invadida pelo negrume. Verificamos que "empobrece-se [...] o poetizado, o pintado, o composto" (ADORNO, 2008b, p. 69).

O moderno se caracteriza então pela fealdade, pela dissonância, pelo negro, pelas ruínas, bem como pela sua adesão à crueldade e à escatologia. O belo não é um valor intrinsecamente artístico como foi outrora. Segundo Adorno, "A arte nova, pela espiritualização, evita - como deseja a cultura pedante - a contaminação pelo verdadeiro, pelo belo e pelo bem" (ADORNO, 2008b, p. 147).

A arte é, mais claramente do que nunca, a expressão do sofrimento reificado pela sociedade. Isso se deve porque "[...] tomou sobre si todas as trevas e culpas do mundo. Toda a sua felicidade apóia-se em reconhecer a infelicidade; toda a sua beleza, em subtrair-se à aparência do belo" (ADORNO, 2002, p. 107).

Percebe-se por esse excerto que Adorno recorre às categorias de catástrofe, feio, pobreza, ruínas, dentre outras, para explicar a arte nova dando a essas características um significado particular. Outros filósofos e críticos certamente puderam constatar e analisar a invasão da arte moderna pelo feio. Entretanto, a particularidade de Adorno ao interpretar essas inovações no vocabulário artístico foi o fato de ele as ver como a única alternativa que restou à arte que não se restringia à falsa reconciliação com o mundo administrado. 
É possível concordar com Hohendahl (2005) em sua defesa de que o feio ocupa um lugar importante na estética de Adorno, e em particular na compreensão da arte moderna e das vanguardas, porque ele se opõe à comercialização do belo pela indústria cultural. Nesse sentido, é precisamente a violação da estética tradicional que salvaguarda o lugar crítico das vanguardas em relação à indústria cultural ${ }^{3}$.

$\mathrm{O}$ belo e a harmonia são tradicionalmente ideais da arte europeia. A arte que quisesse então desafiar sua própria tradição deveria incluir em si o feio. Não menos interessante é o fato de Adorno reconhecer que muitos desses aspectos da vanguarda europeia no que se refere à criação do desarmônico e do esteticamente desagradável teriam sido influenciados por culturas estrangeiras. Foram notáveis as influências que, por exemplo, nas artes plásticas, os cubistas tiveram da África (influência que talvez tenha faltado ao filósofo notar como positiva em outras modalidades artísticas, como, por exemplo, o jazz).

\section{Recusa dos discursos escatológicos e inclusão da escatologia na arte}

Bowie afirma, não sem razão, que, quando se fala da filosofia de Adorno, já se estabeleceu o clichê de relembrar seu questionamento acerca da possibilidade de se fazer poesia após Auschwitz ${ }^{4}$ A demasiadamente citada frase em questão é recorrentemente lembrada por aqueles que buscam enfatizar o pessimismo cultural de Adorno. Não é possível esquecer que, em consonância com essas críticas recorrentes, encontra-se a alcunha de “apocalíptico" dada por Umberto Eco a Adorno.

\footnotetext{
3 "Adorno introduces a second line of argument, namely the relevance of the ugly for modern art, and for the avant-garde in particular. In the context of modernist aesthetics the reversal between the beautiful and the ugly becomes necessary for a defense of the artwork against the impact of the culture industry and its commercialization of the beautiful. Adorno mentions "Jugendstil" as a primary example for this process. The autonomy of the artwork depends on its oppositional force, a quality that is enhanced by the ugly. It is precisely the violation of the traditional aesthetic code that separates the advanced artwork from the threat of the culture industry" (HOHENDAHL, 2005, p. 170).

"Adorno introduz uma segunda linha de argumentação, voltada à relevância do feio para a arte moderna e para a vanguarda em particular. No contexto da estética modernista a inversão entre o belo e o feio se torna necessária para a defesa da obra de arte contra o impacto da indústria cultural e a comercialização do belo por ela realizada. Adorno menciona a "Jugendstil" como um exemplo primário desse processo. A autonomia da obra de arte depende da sua força oposicional, uma qualidade que é reforçada pelo feio. É precisamente a violação do código estético tradicional que separa a obra avançada da ameaça da indústria cultural.” (Tradução nossa)

4 "Too often the image of Adorno's philosophy is summed up in (sometimes misquoted) slogans like 'no poetry after Auschwitz' and his work is assumed to express an allenveloping cultural pessimism" (BOWIE, 1997, p. 266). "Muito frequentemente a imagem da filosofia de Adorno é resumida em (às vezes mal-citados) slogans tais como "a impossibilidade de fazer poesia após Auschwitz" e se assume que seu trabalho expressa todo um ar de pessimismo cultural.” (Tradução nossa)
} 
Na Teoria estética, Adorno afirma que tudo o que há para se dizer sobre arte tem sua legitimidade ameaçada. Entretanto, Adorno não adere a teorias escatológicas da arte que defendem sua morte ou decadência, considerando-as no mínimo prematuras. Colocam-se então as questões: como é possível conciliar a recusa de Adorno aos discursos escatológicos sobre arte e, ao mesmo tempo, assumir seu pessimismo cultural? Seria, no final das contas, essa recusa marca de um possível otimismo de Adorno em relação aos mais variados diagnósticos de fim da arte?

Sua rejeição a esse tipo de ideias escatológicas culmina em sua classificação da fillosofia da arte hegeliana como "nostalgia classicista" e também como "estética do status quo":

A produção artística que não se deixa extraviar no impulso contra $\mathrm{o}$ endurecimento da vida, portanto a arte verdadeiramente ingênua, converte-se no que, segundo as regras do jogo do mundo convencional, se chama não ingênuo [...] Hegel, e ainda mais agudamente Jochmann, reconheceram isso, mas estavam de tal modo prisioneiros do classicismo que, por causa desse elemento infantil, profetizaram o fim da arte (ADORNO, 2008b, p. 511).

Adorno discorda do diagnóstico hegeliano do fim da arte, reconhecendo que a arte deve ser compreendida pelo seu tornar-se.

A fim de compreender essa perspectiva, deve-se atentar para a leitura que é feita da noção hegeliana de arte como intuição sensível da Ideia. Se, por um lado, há um progresso significativo no reconhecimento do espírito como substancial à arte; por outro, para Adorno, a filosofia hegeliana ainda reserva um papel menor do que o devido ao espírito na compreensão do fenômeno artístico:

O idealismo filosófico, porém, de modo algum era tão inclinado à espiritualização estética como esta construção o permitia esperar. Comportava-se antes como defensor daquele elemento sensível, que era eliminado pela espiritualização; segundo a própria expressão de Hegel, esta doutrina do belo como aparência sensível da Ideia era afirmativa enquanto apologia da imediatidade considerada como algo de plenamente significativo; a espiritualização radical é disso o contrário (ADORNO, 2008b, p. 143).

É o espírito que determina que os momentos sensíveis da obra sejam mediatizados. A crescente espiritualização da arte moderna, por sua vez, volta-se contra o puramente sensual nas obras. A espiritualização da arte deriva do processo de autoconsciência do sujeito, não mais passível de ser ignorado pela arte crítica. "Só enquanto espírito é a arte a contradição da realidade empírica, que se orienta para a negação determinada da organização do mundo existente" (ADORNO, 2008c, p. 141). 
Em uma interessante nota de rodapé em que se discute a dissolução da arte na Filosofia da Nova Música, o sucesso da arte crítica é relacionado ao grau de autoconhecimento apresentado pela obra, e a esses elementos Adorno credita parte da possibilidade de sobrevivência da arte. Assim,

\begin{abstract}
O que na verdade deriva da obra de arte "aurática" ou da obra de arte fechada no período de sua dissolução depende da relação que sua própria dissolução tenha com o conhecimento. Se esta dissolução é cega e inconsciente a obra de arte cai na arte de massa da reprodução técnica. [...] Como autoconsciente, em compensação, a obra de arte torna-se crítica e fragmentária. Schönberg e Picasso, Joyce e Kafka e até Proust, estão de acordo em que hoje as obras de arte têm uma possibilidade de sobreviver. E isto permite de novo a especulação históricofilosófica. A obra de arte fechada é a obra de arte burguesa, essa obra mecânica, pertencente ao fascismo; a obra de arte fragmentária indica, no estado da negatividade total, a utopia (ADORNO, 2002, p. 102).
\end{abstract}

Deve-se considerar que há pelo menos dois aspectos importantes para a melhor aproximação do diagnóstico de Adorno, e que esses aspectos encontram-se entrelaçados. Primeiro, há a noção já mencionada de que a arte se torna cada vez mais autoconsciente. Segundo, Adorno consideraria a fragmentação da obra de arte, em suas várias facetas, como a possibilidade de a arte se tornar crítica. Tanto na pintura como na literatura e na linguagem musical o filósofo vê exemplos de como a fragmentação artística possibilitou a persistência da utopia. A autoconsciência da arte é o que faz dela mais intelectualista e espiritual, tornando-a refratária aos apelos da ingenuidade artística entendida em seu sentido clássico (e dissociado da reflexividade).

A fragmentação derivada da autoconsciência, por sua vez, corresponde à tendência das obras à catástrofe, uma vez que ela advém do empobrecimento do sujeito no mundo administrado, como veremos a seguir. Consequência disso é que, à já comentada crítica dos gêneros realizada pela arte nova segue-se a adoção de materiais dissonantes e repelentes. Esses elementos estão interligados na arte nova e utópica, e isso que possibilita que ela se constitua como negação determinada da sociedade. De acordo com isso, "O primado do espírito na arte e a irrupção do que antes era tabu são dois lados do mesmo estado de coisas. Aplica-se ao que a sociedade já não aprova e pré-forma e transforma-se assim numa relação social de negação determinada" (ADORNO, 2008b, p. 147).

Levando-se em conta sua rejeição ao classicismo artístico, a questão de como é possível fazer poesia após Auschwitz poderia, dessa forma, ser parcialmente respondida por uma frase de Bertolt Brecht citada por Adorno justamente no momento em que discute a atração da arte moderna pelo negro em sua Teoria estética: "Que tempos são esses em que falar de 
árvores é quase uma ofensa porque se faz silêncio sobre tantos crimes!" (BRECHT apud ADORNO, 2008b, p. 68) ${ }^{5}$.

Como demonstra sua valorização da dissonância de Schönberg e do mutismo de Samuel Beckett, o filósofo encontra utopia mesmo em obras acentuadamente catastróficas. A fórmula stendhaliana de promesse de bonheur (promessa de felicidade) se une a uma arte profundamente marcada pela negatividade: "O Novo enquanto criptograma é a imagem da decadência; só através da sua negatividade absoluta é que a arte exprime o inexprimível, a utopia. Nessa imagem reúnem-se todos os estigmas do repelente e do repugnante na arte moderna" (ADORNO, 2008b, p. 58).

Adorno explica que a arte nova não comporta uma cópia da utopia. É apenas "cifra do seu potencial":

\begin{abstract}
Pela recusa intransigente da aparência de reconciliação, a arte mantém a utopia no seio do irreconciliado, consciência autêntica de uma época, em que a possibilidade real da utopia o facto de a terra, segundo o estado das forças produtivas, poder ser aqui e agora o paraíso - se conjuga num ponto extremo com a possibilidade da catástrofe total. Na imagem da utopia - não cópia, mas cifra do seu potencial - reaparece o traço mágico da mais remota pré-história da arte sob o sortilégio integral; como se ela, através da sua imagem, quisesse conjurar a catástrofe. O tabu acerca do telos histórico é a única legitimação daquilo por que o Novo se compromete no plano político e prático, do seu aparecimento como fim em si (ADORNO, 2008c, p. 58).
\end{abstract}

No entanto, ela só pode se constituir enquanto tal a partir de sua semelhança com a decadência e a catástrofe. Isso é claramente defendido pelo filósofo quando ele afirma que "Para subsistir no meio dos aspectos mais extremos e sombrios da realidade, as obras de arte que não querem vender-se como consolação deviam tornar-se semelhantes a eles" (ADORNO, 2008b, p. 68).

Deve-se considerar sobre essa questão outra frase antológica de Adorno acerca da Segunda Guerra Mundial: o imperativo categórico apontado por Adorno é o de que não se pode esquecer Auschwitz. E o que se afigura após uma leitura atenta da Teoria estética é que a poesia pósAuschwitz deve ter Auschwitz incrustada em si. A possibilidade de se fazer poesia após os excruciantes eventos da guerra se encontra justamente na inclusão desses elementos catastróficos na poesia, ainda que esses apareçam pela perspectiva de que não podem ser completamente expressos.

O campo de concentração da Segunda Guerra Mundial é símbolo de toda barbárie. Nesse sentido, a arte crítica em relação à sociedade é justamente aquela que assume sua relação com o negrume, a fealdade, a

\footnotetext{
${ }^{5}$ No original em alemão, "Was sind das für Zeiten, wo Ein Gespräch über Bäume fast ein Verbrechen ist. Weil es ein Schweigen über so viele Untaten einschließt!“.
} 
catástrofe, a decadência, a pobreza. Inversamente, "A injustiça, que toda a arte engraçada, sobretudo a de divertimento, gera é uma injustiça para com os mortos, para com a dor acumulada e muda" (ADORNO, 2008b, p. 69). Indubitavelmente, Adorno recusa a arte ingênua em sua capacidade de trazer de volta a cor a um mundo sombrio. Isso já não é mais possível.

As "árvores" da frase de Brecht simbolizam todo tema imediata e tradicionalmente poético que já não mais é absorvido por uma arte crítica, que se constitua como antagonista da sociedade. A vocação da arte torna-se, então, a de libertar o sofrimento reificado.

A principal testemunha a este propósito seria o quadro de Picasso Guernica que, por uma rigorosa incompatibilidade com o realismo prescrito, adquire justamente, graças a uma construção inumana, aquela expressão que acusa o seu caracter de protesto, para lá de todo o mal-entendido contemplativo. As zonas socialmente críticas das obras são aquelas onde se sofre, quando, na sua expressão, a inverdade da situação social aparece historicamente determinada. A isso reage efectivamente a cólera (ADORNO, 2008b, p. 358).

É preciso deixar de calar sobre os crimes, de modo que as árvores são abandonadas em favor da assunção do empobrecimento. Nesse sentido, "As artes mais progressistas impelem este empobrecimento até a beira do mutismo" (ADORNO, 2008b, p.69). Ao tematizar o mutismo e o empobrecimento na arte, Adorno segue uma sugestão de Walter Benjamin em seu texto O Narrador: Considerações sobre Nikolai Leskov (1994), quando este assinalou que a guerra havia legado a seus participantes experiências incomunicáveis. Efetivamente, Adorno, em carta de dirigida a Walter Benjamin, aprova completamente a análise de seu colega acerca da dificuldade de narrar:

[...] só posso expressar a mais plena concordância com a sua perspectiva histórico-filosófica de que o narrar não é mais possível. Esse é um pensamento que me é familiar, e para muito além das sugestões da Teoria do romance nesse sentido, algo que me era evidente havia anos, antes mesmo de poder analisá-lo teoricamente (ADORNO; BENJAMIN, 2012, p. 230).

$\mathrm{Na}$ análise de Benjamin, a incomunicabilidade consistia no choque e na impossibilidade de elaborar os acontecimentos vividos sobretudo no horror da guerra, mas também da dificuldade de elaborar a experiência de desmoralização advinda do capitalismo:

Com a guerra mundial tornou-se manifesto um processo que continua até hoje. No final da guerra, observou-se que os combatentes voltavam mudos do campo de batalha, não mais ricos, e sim mais pobres em experiência comunicável. E o que 
se difundiu dez anos depois, na enxurrada de livros sobre a guerra, nada tinha em comum com uma experiência transmitida de boca em boca. Não havia nada de anormal nisso. Porque nunca houve experiências mais radicalmente desmoralizadas que a experiência estratégica pela guerra de trincheiras, a experiência econômica pela inflação, a experiência do corpo pela guerra de material e a experiência ética pelos governantes (BENJAMIN, 1994, p. 198).

Tal diagnóstico benjaminiano parece ter influenciado sobremaneira Adorno. Não é gratuito que ele tenha, na Teoria estética, versado sobre a tendência catastrófica da arte moderna. Entretanto, ao invés de procurar narradores que resistam ao processo de declínio da experiência, Adorno elogia as ruínas em que se converteu a arte. Em Notas de Literatura I, ele comenta sobre o caráter sui generis do narrador contemporâneo:

[...] o que se desintegrou foi a identidade da experiência, a vida articulada e em si mesma contínua, que só a postura do narrador permite. Basta perceber o quanto é impossível, para alguém que tenha participado da guerra, narrar essa experiência como antes uma pessoa costumava contar suas aventuras. A narrativa que se apresentasse como se o narrador fosse capaz de dominar esse tipo de experiência seria recebida, justamente, com impaciência e ceticismo (ADORNO, 2003, p. 56).

A fragmentação da narrativa é análoga à fragmentação da linguagem musical. É papel da arte abrir caminho não para terras paradisíacas e utópicas, mas sim para uma "terra de ninguém", expressão evocada por Adorno tanto na Filosofia da Nova Música como na Teoria estética.

Por essa razão ele afirma que "Há mais prazer na dissonância que na consonância" (ADORNO, 2008b, p. 69), reconhecendo na música de Schönberg um caráter especial. O filósofo identifica em Pierrot Lunaire a primeira vez em que alguns desses elementos catastróficos teriam vindo à tona na arte moderna.

O prazer derivado da consonância é largamente explorado pela indústria cultural. A arte nova, em oposição às mercadorias culturais, lança mão da dissonância. Adorno rejeita a "estética culinária" em nome da espiritualização das obras. Por diversas vezes Adorno critica a tendência a perceber a obra de arte apenas em sua imediatidade sensível. A recepção da obra de arte não deve se ater, por exemplo, somente à excitação sentida durante uma cena de perseguição de carro em um filme de ação típico da indústria cultural. Adorno idealiza uma recepção que perceba a obra enquanto construto, e assim se dê conta das relações existentes entre suas partes e o todo. Por essa razão, é preferível que a arte nova seja ascética em um mundo abarrotado de produtos culturais sensuais consumidos a partir do imediatismo sensível. "O burguês deseja que a arte seja voluptuosa e a vida ascética", comenta Adorno, para depois concluir que "o contrário seria 
melhor" (ADORNO, 2008b, p. 29). Nesse medida, não causa estranheza que a arte espiritualizada só propicie prazer pela dissonância.

Outro adjetivo que Adorno associa à arte nova, ainda que menos recorrentemente, é o de "cruel". Desse modo são os romances de Kafka, bem como muito do que se produz na arte nova. A arte deve sobrepujar em crueldade e desumanidade a realidade social. Toda arte que não atente para isso será suspeita de ficar a dever em relação à sua criticidade. É dessa forma que a arte expressa as tensões presentes na sociedade. Por isso Adorno complementa, ainda em diálogo com a filosofia hegeliana, que justamente isso impossibilita a condenação da arte:

O tema hegeliano da arte como consciência da infelicidade confirmou-se para lá de tudo o que ele podia imaginar. $\mathrm{O}$ tema hegeliano tornou-se assim oposição contra a sua própria condenação da arte, contra um pessimismo cultural, que relevava o seu optimismo teológico recentemente secularizado e a expectativa de uma liberdade verdadeiramente realizada. $\mathrm{O}$ obscurecimento do mundo torna racional a irracionalidade da arte: mundo radicalmente ensombrado. $\mathrm{O}$ que os inimigos da arte nova, com instinto mais sagaz do que os seus apologistas ansiosos, chamam a sua negatividade é a própria substância do que foi recalcado pela cultura estabelecida (ADORNO, 2008b, p. 37).

Na interpretação de Adorno, foi possível a Hegel ser pessimista em relação ao futuro da arte porque ele o era insuficientemente em relação ao curso do mundo. Coube a Adorno realizar essa inversão na estética. É prematuro decretar o fim da arte não só porque ainda precisamos dela em face do mundo administrado, mas também porque é justamente ao não se colocar como consolação que a arte expressa o que foi recalcado pela cultura.

\section{O empobrecimiento e o mutismo como discurso autorreflexivo sobre a catástrofe}

Com o fito de analisar a arte nova que estava sendo produzida, Adorno diagnostica uma tendência da arte pouco notada entre seus comentadores:

Em viva oposição à arte tradicional, a arte nova salienta o aspecto outrora oculto do fabricado, do produzido. [...] Quanto mais na arte se deve fabricar, buscar e inventar, menos é certo que se consiga fabricar e inventar. A arte radicalmente fabricada reduz-se ao problema da sua elaboração (ADORNO, 2008b, p. 49).

É possível verificar que Adorno, a exemplo de outros estetas, reconheceu a crescente tendência da arte a tematizar sua própria elaboração. O papel da reflexividade e da espiritualização no potencial crítico da arte 
moderna não é pequeno. Em diversos momentos, Adorno critica a ideia de que a arte é pura e tão somente intuição.

$\mathrm{Na}$ sua relação com o não-dominado, a espiritualização é antinómica. Porque ela limita sempre ao mesmo tempo os momentos sensíveis, o espírito torna-se para ela fatalmente um ser sui generis e trabalha assim, de acordo com a sua tendência imanente, contra a arte. A crise da arte é acelerada pela espiritualização que se opõe a que as obras de arte sejam vendidas a saldo como valores de engodo. [...] O êxito da espiritualização da arte é que decide se esta sobreviverá ou se se virá a cumprir a profecia hegeliana do seu fim, predição que, no mundo tal como ele se tornou, desembocaria na confirmação e na acentuação não reflectida, realista no sentido abominável do termo, do que existe. Sob este aspecto, a salvação da arte é eminentemente política, mas também incerta em si tal como ameaçada pelo curso do mundo (ADORNO, 2008b, p. 149).

No entanto, algo que ainda deve ser destacado é como Adorno percebia que a arte se torna autorreflexiva inclusive no que diz respeito à sua própria impossibilidade.

Para Adorno, os tempos atuais necessitam da resistência da arte, e isso na medida em que ela periga se tornar impossível para o sujeito atual: "A isso corresponde uma necessidade objetiva, a indigência do mundo, contrária à necessidade subjetiva da arte, necessidade que é hoje apenas a necessidade ideológica dos homens; a arte com mais nada pode contar senão com esta necessidade objetiva" (ADORNO, 2008b, p. 53).

É esse o sentido que o empobrecimento, exemplificado pelo narrador com dificuldade de narrar, dentre outras estratégias da arte nova, representa nos rumos da arte. Sobre isso, vale levar em consideração o comentário de Adorno acerca de Kafka:

[...] Enquanto que os escritos de Kafka feriam a compreensão do leitor de romance pela impossibilidade relevante e empírica da narrativa, tornou-se, justamente em virtude de tal irritação, compreensível a todos. A opinião proclamada em uníssono pelos ocidentais e pelos estalinistas sobre a incompreensibilidade da arte moderna continua a ilustrar este fenômeno; é falsa porque trata a recepção como uma grandeza fixa e suprime as irrupções na consciência, de que são capazes as obras incompatíveis. No mundo administrado, a forma adequada em que são recebidas as obras de arte é a da comunicação do incomunicável, a emergência da consciência reificada (ADORNO, 2008b, p. 297).

Se podemos nos fiar à fórmula adorniana famosa de que forma é conteúdo sedimentado, devemos atentar ao fato de que os escritos de Kafka são mudos e, no entanto, expressam em sua forma a consciência reificada: 
A consciência reificada que pressupõe e confirma a inelutabilidade e a imutabilidade do ente é, enquanto herança do antigo sortilégio, a forma moderna do mito do sempresemelhante. O estilo épico de Kafka é, no seu arcaísmo, a mimese da reificação. Ao ter de recusar-se a transcender o mito, a sua obra torna conhecível em si o contexto de cegueira da sociedade através do como, da linguagem. Para a sua narrativa, a absurdidade é tão evidente como o é para a sociedade. São socialmente mudos os produtos que realizam o seu «deve», ao restituirem tel quel por si mesmos o elemento social de que tratam e ao gloriarem-se de reflectir esta mudança de tema com a segunda natureza (ADORNO, 2008b, p. 347).

A tendência da arte de tematizar sua própria elaboração enquanto empobrecida também é apontada por inúmeras outras passagens da obra de Adorno dedicada à estética, como, por exemplo, em suas análises da arte de Samuel Beckett:

Nos últimos anos, achou-se prazer em censurar a Samuel Beckett a repetição das suas concepções; ele expôs-se a esta censura de uma maneira provocante. A sua consciência foi justamente tanto a da necessidade de continuação como a da sua impossibilidade. [...] As suas novelas, a que ele sardonicamente dá o nome de romances, oferecem tão pouco descrições objectivas da realidade social como representam segundo um mal-entendido muito difundido - reduções a relações humanas fundamentais, ao mínimo de existência que subsistiria in extremis. No entanto, estes romances tocam estratos fundamentais da experiência hic et nunc, experiência do que é agora, e fazem-nos entrar numa dinâmica paradoxal. São tão marcados pela perda do objecto motivada objectivamente como pelo seu correlato, o empobrecimento do sujeito (ADORNO, 2008b, p. 55).

dadaísmo:

Nesse mesmo espírito, Adorno ressalta o aspecto de verdade do

No entanto, a falta de ressonância social não foi a única causa de decadência do expressionismo; não é preciso insistir demasiado neste ponto, uma involução das disponibilidades, a totalidade da recusa, termina numa indigência total, no grito ou no gesto irremediavelmente impotente, literalmente no Da-Da. Muda-se em brincadeira tanto a respeito do conformismo como de si mesmo, porque reconhece a impossibilidade da objectivação artística, a qual, no entanto é postulada por toda a manifestação artística, quer queira quer não; sem dúvida, só resta gritar (ADORNO, 2008b, p. 54). 
Adorno reconhece que a reflexividade artística se intensifica e que começa a se associar à noção de que a arte periga não mais objetivar-se em uma cultura administrada, na qual predomina a "vida lesada". No entanto, é justamente a expressão dessa impossibilidade que faz com que a arte se mantenha utópica e realize a crítica imanente da sociedade.

Ao afirmar que "A única via que permanece aberta às obras de arte como via do seu êxito é também a sua impossibilidade progressiva" (ADORNO, 2008b, p. 306), Adorno indubitavelmente aponta para uma arte nova que só se torna possível mediante a assunção dos desafios colocados para a arte no mundo administrado. Esses desafios tomam tal proporção que colocam a arte na iminência de sua própria impossibilidade. Diante disso, Adorno sugere, em suas considerações estéticas, que a arte nova é não só extremamente relacionada à ideia de catástrofe como também profundamente associada a um diagnóstico catastrófico sobre si mesma. Nesse sentido, ele observa e valoriza uma espécie de "poética da impossibilidade" pela qual as ruínas, a destruição e o negro adquirem qualidade utópica que permite que a arte se torne crítica em relação à cultura administrada. 


\section{Refrencias bibliográficas}

ADORNO, Theodor W.; BENJAMIN, Walter. Correspondência, 19281940. São Paulo: Unesp, 2012.

ADORNO, Theodor Wiesengrund. Filosofia da nova música. São Paulo: Perspectiva, 2002.

ADORNO, Theodor W. Notas de literatura I. São Paulo: Duas Cidades Ed. 34, 2003.

ADORNO, Theodor Wiesengrund. Minima Moralia: reflexões a partir da vida lesada. Rio de Janeiro: Beco do Azougue, 2008a.

ADORNO, Theodor Wiesengrund. Teoria estética. Lisboa: Edições 70, 2008b.

BENJAMIN, Walter. O Narrador. Considerações sobre a obra de Nikolai Leskov. In: Magia e Técnica, Arte e Política: ensaios sobre literatura e história da cultura. Obras escolhidas I. 7 ed. São Paulo: Brasiliense, 1994. p. 165-196.

BOLAÑOS, Paolo Adriatico. The Critical Role of Art: Adorno between Utopia and Dystopia. Kritike, v. 1, n.1, jun./2007, p. 25-31.

BOWIE, Andrew. From Romanticism to Critical Theory: The Philosophy of German Literary Theory. London and New York: Routledge, 1997.

HOHENDAHL, Peter Uwe. The Concept of the Ugly in Adorno's Aesthetic Theory. Cultural Critique, n. 60, 2005, p.170-196.

Autor(a) para correspondência: Luciana Molina Queiroz, Universidade Estadual de Campinas, Instituto de Filosofia e Ciências Humanas, R. Cora Coralina, 100, Cidade Universitária, CEP 13083-896, Campinas - SP, Brasil. lucianamqueiroz@gmail.com 